\title{
Circulating Lipopolysaccharide-Binding Protein and Carotid Intima-Media Thickness in Obstructive Sleep Apnea
}

\author{
I. TROJOVA ${ }^{1}$, M. KOZAROVA ${ }^{2}$, D. PETRASOVA ${ }^{3}$, Z. MALACHOVSKA ${ }^{2}$, \\ I. PARANICOVA ${ }^{1}$, P. JOPPA $^{1}$, R. TKACOVA ${ }^{1}$
}

${ }^{1}$ Department of Respiratory Medicine and Tuberculosis, P. J. Safarik University in Kosice, Medical Faculty and L. Pasteur University Hospital, Kosice, Slovakia, ${ }^{2}$ Fourth Department of Internal Medicine, P. J. Safarik University in Kosice, Medical Faculty and L. Pasteur University Hospital, Kosice, Slovakia, ${ }^{3}$ Laboratory of Research Biomodels, P. J. Safarik University in Kosice, Medical Faculty, Kosice, Slovakia

Received March 7, 2017

Accepted June 19, 2017

On-line November 10, 2017

\section{Summary}

Circulating lipopolysaccharide-binding protein (LBP), a metabolic endotoxemia marker, was identified as an independent predictor of atherosclerosis. Although increases in carotid intima-media thickness (CIMT) were repeatedly reported in obstructive sleep apnea (OSA), neither the role of OSA in metabolic endotoxemia nor of LBP in early atherosclerosis were explored in patients with OSA. At a tertiary university hospital we investigated the relationships between OSA, LBP and CIMT in 117 men who underwent full polysomnography and CIMT assessment by B-mode ultrasound. Circulating LBP concentrations and average CIMT increased from patients without OSA to those with mild-moderate and severe OSA (from $32.1 \pm 10.3$ to $32.3 \pm 10.9$ to $38.1 \pm 10.3 \mu \mathrm{g} \cdot \mathrm{ml}^{-1}, \mathrm{p}=0.015$; from $0.52 \pm 0.09$ to $0.58 \pm 0.06$ to $0.62 \pm 0.10 \mathrm{~mm}, \mathrm{p}=0.004$, respectively). Oxygen desaturation index (ODI) was a predictor of serum LBP levels independent of age, waist-to-hip ratio (WHR), smoking, hypertension, $\mathrm{HDL}$ cholesterol, triglycerides and fasting glucose [p (ANOVA) $\left.=0.002, r^{2}=0.154\right]$, with no independent effect of the ODI*WHR interaction term on LBP. Furthermore, serum LBP predicted CIMT independently of known risk factors of atherosclerosis including obesity $\left(p<0.001, r^{2}=0.321\right)$. Our results suggest that OSA severity contributes to metabolic endotoxemia in patients with OSA independently of obesity, and that LBP might represent a contributing factor promoting early atherosclerosis in such patients.

\section{Key words}

Lipopolysaccharide-binding protein • Obstructive sleep apnea • Carotid atherosclerosis • Intima-media thickness • Endotoxemia

\section{Corresponding author}

R. Tkacova, Department of Respiratory Medicine, P. J. Safarik University, Medical Faculty and L. Pasteur University Hospital, Rastislavova 43, 04190 Kosice, Slovakia. Fax: +421 55615 2664. E-mail: ruzena.tkacova@upjs.sk

\section{Introduction}

Obstructive sleep apnea (OSA) is characterized by repeated episodes of upper airway occlusion during sleep, which are associated with hypoxia and arousals from sleep. Acutely, repetitive apneas and hypopneas trigger surges in sympathetic nervous system activity, blood pressure and heart rate. Chronically, patients with OSA are at increased risk for arterial hypertension, stroke, and myocardial ischemia and have an increased cardiovascular morbidity and mortality (Shah et al. 2010, Punjabi et al. 2009, Marin et al. 2005). In addition, signs of subclinical atherosclerosis as evidenced by increased carotid intima-media thickness (CIMT) were reported in OSA including patients with no overt cardiovascular disease (Monneret et al. 2010, Fox et al. 2014, Damiani et al. 2015, Drager et al. 2005). 
Metabolic endotoxemia reflected by serum lipopolysaccharide-binding protein (LBP) levels was identified to represent an independent predictor of coronary atherosclerosis in the LURIC study (Lepper et al. 2014) thus extending the list of recognized pathogenetic mechanisms of atherosclerosis such as aging, obesity-related metabolic disturbances and inflammatory processes (Libby 2002). Originally, Cani et al. (2008) identified bacterial lipopolysaccharide (LPS) as a triggering factor of insulin resistance and weight gain, and defined its negative effects as "metabolic endotoxemia". LBP binds LPS, and elevated circulating concentrations of this biomarker are considered a marker of metabolic endotoxemia in clinical studies (GonzalezQuintela et al. 2013). Several reports documented an association between serum LBP and prevalent coronary artery disease, and identified LBP as an independent predictor of coronary atherosclerosis (Lepper et al. 2011, Lepper et al. 2007, Szeto et al. 2008, Serrano et al. 2013). Nevertheless, the effects of OSA on serum LBP and the potential links between metabolic endotoxemia and CIMT in such patients remain largely unexplored. Therefore, we investigated the effects of OSA severity on serum LBP, and tested the hypothesis that serum LBP concentrations relate to CIMT in patients with OSA.

\section{Methods}

\section{Subjects}

The study was conducted in the sleep unit at the tertiary referral university hospital. Clinically stable men who had been referred for evaluation of suspected OSA were enrolled to the study. Exclusion criteria were history of known cardiovascular disease (CVD), angina, myocardial infarction, stroke, congestive heart failure, chronic respiratory diseases other than OSA, type 1 or 2 diabetes, hereditary metabolic disorders, hypothyroidism, chronic inflammatory diseases and regular use of sedatives, antidepressant or antipsychotic medication or alcohol. The history was retrieved from complete patients' charts as provided by general practitioners. Anthropometric measurements were obtained in the morning after the polysomnographic examination with the patient standing erect. Body weight, height, neck circumference, waist circumference and hip circumference were measured and recorded. Neck circumference was measured at the level of the cricothyroid membrane; waist circumference at the midpoint between the costal margin and the iliac crest at the end of normal expiration; hip circumference at the level of the greater trochanter. Body mass index (BMI) was defined as weight/height ${ }^{2}\left(\mathrm{~kg} / \mathrm{m}^{2}\right)$. The waist-to-hip ratio (WHR) was also calculated. The study was in agreement with Helsinki protocol and was approved by the L. Pasteur University Hospital ethics committee. All subjects provided written informed consent before entry to the study.

\section{Polysomnography}

All participants underwent attended diagnostic overnight polysomnography (Alice 4; Respironics Inc., Murrysville, Pennsylvania, USA), comprising continuous recording of electroencephalograph, electrooculography, electromyography, electrocardiography, thoracic and abdominal impedance belts for respiratory movements, thermistor for nasal and oral airflow, pulse oximetry and microphone for snoring. All records were scored manually following the American Academy for Sleep Medicine (AASM) 2012 guidelines (Berry et al. 2012). Apnea was identified as a drop in airflow of $\geq 90 \%$ from the baseline excursion for $\geq 10 \mathrm{~s}$; hypopnea was defined as a reduction in airflow of $\geq 50 \%$ of baseline for $\geq 10 \mathrm{~s}$ accompanied either by a decrease in hemoglobin saturation for $\geq 3 \%$, an EEG-recorded arousal, or both. The apnoe-hypopnoe index (AHI) was defined as the number of apnoe and hypopnoe events per hour of sleep. Oxygen desaturation index (ODI) was defined as the number of oxygen desaturations of hemoglobin of $\geq 3 \%$ per hour of sleep. In addition, the length of time with an arterial oxygen saturation measured by pulse oximetry $\left(\mathrm{SpO}_{2}\right)<90 \%$ was used to assess the degree of nocturnal hypoxia. The classification of OSA severity was based on AASM guidelines: Mild: $\mathrm{AHI} \geq 5$ and $<15$ episodes. $\mathrm{h}^{-1}$; moderate: $\mathrm{AHI} \geq 15$ and $<30$ episodes. $\mathrm{h}^{-1}$, and severe: $\mathrm{AHI} \geq 30$ episodes. $\mathrm{h}^{-1}$ (Berry et al. 2012).

\section{Biochemical measurements}

Peripheral venous blood samples were collected between 6-7 a.m. following an overnight $12 \mathrm{~h}$ fast and polysomnography. Blood sample was taken from the antecubital vein and after immediate centrifugation, aliquots of plasma and serum were stored at $-70{ }^{\circ} \mathrm{C}$ until analysis. Fasting cholesterol, triglycerides, high-density lipoprotein (HDL) cholesterol, apolipoprotein A-I (ApoA-I), and apolipoprotein B (ApoB) were measured by routine enzymatic methods. Low-density lipoprotein (LDL) cholesterol was derived using the Friedewald 
equation. Serum insulin was determined with electrochemiluminiscence immunoassay kits (Elecsys) on Roche Elecsys 1010/2010 and modular analytics E170 immunoassay analyzers (Roche Diagnostics $\mathrm{GmbH}$, Mannheim, Germany); plasma glucose was measured by the glucose oxidase method on a Beckman autoanalyzer. Insulin resistance was estimated by the homeostasis model assessment (HOMA-IR) using the following formula: fasting serum insulin $\left(\mathrm{mU}^{-1} \mathrm{l}^{-1}\right) \mathrm{x}$ fasting plasma glucose $\left(\mathrm{mmol}^{-1} \mathrm{l}^{-1}\right) / 22.5$ (Gayoso-Diz et al. 2013). LBP levels were assessed using a commercially available kit based on murine monoclonal antibodies specific for human LBP (Human LBP ELISA, Abnova, Taipei City, Taiwan).

\section{Carotid intima-media thickness}

Measurement of CIMT was done by high-resolution B-mode ultrasound system (Philips HD11XE) equipped with a linear array $7 \mathrm{MHz}$ transducer. 3-lead electrocardiographic signal was obtained along with ultrasound scanning and CIMT was measured at the end-diastole. Semiautomatic border detection program $\mathrm{QLab}^{\odot}$ was used for offline CIMT measurement on the segment of the common carotid artery (CCA) free of atherosclerotic plaque with clearly defined lumen-intima and media-adventitia interfaces. The measurement was done on the far wall of CCA at a distance of at least $10 \mathrm{~mm}$ below its distal end. Values from right and left CIMT were calculated as the mean of three measurements. Average CIMT (mm) was calculated as the mean of the right and left CIMT values (Touboul et al. 2012).

\section{Statistical analysis}

Analyses were conducted using SPSS software for Windows (version 14.0; IBM, Chicago, Illinois, USA); two-tailed $\mathrm{p}<0.05$ was considered significant. The data of continuous variables are presented as mean $\pm \mathrm{SD}$; differences between the groups were analyzed using analysis of variance (ANOVA). Kolmogorov-Smirnov test was used to check for normality of the values distribution within each variable. Chi-square test was used to compare the proportion of categorical variables between groups. Correlation analyses were performed using the Pearson product moment correlation method. Multiple linear regression models were used with LBP as a dependent variable and age, WHR, smoking, hypertension, ODI, serum fasting glucose, triglycerides and HDL cholesterol levels as independent variables. Furthermore, multiple linear regression models were used to assess independent predictors of CIMT.

\section{Results}

\section{Characteristics of the subjects}

One hundred and seventeen subjects participated in the study; 10 had no OSA, 50 suffered from mild to moderate, and 57 from severe OSA. Basic demographic characteristics and polysomnographic findings in the study groups are summarized in Table 1. Higher age, BMI, neck circumference, waist-to-hip ratio, systolic and diastolic blood pressure (BP) were all associated with greater severity of OSA. In the entire cohort, $35 \%$ of patients were hypertensive, and were using the following anti-hypertensive drugs: angiotensin-converting enzyme inhibitors $(n=25)$, sartans $(n=6)$, diuretics $(n=6)$, calcium-antagonists $(n=14)$ and beta-blockers $(n=17)$.

\section{Serum lipids and insulin sensitivity}

Serum LDL/HDL ratio, atherogenic index, ApoB levels, and ApoB/ApoA ratio significantly increased from patients without OSA to those with mildmoderate and severe OSA $(\mathrm{p}=0.019, \mathrm{p}=0.005, \mathrm{p}=0.030$, $\mathrm{p}=0.046$, respectively) (Table 2 ). In addition, fasting glucose, insulin and HOMA-IR all increased with greater severity of OSA; patients with severe OSA had significantly higher HOMA-IR compared to participants with no OSA $(\mathrm{p}<0.05)$.

\section{Circulating $L B P$}

Circulating LBP concentrations increased from patients without OSA to those with mild-moderate and severe OSA (from $32.1 \pm 10.3$ to $32.3 \pm 10.9$ to $38.1 \pm 10.3 \mu \mathrm{g} \cdot \mathrm{ml}^{-1}, \mathrm{p}=0.015$ ) (Fig. 1). Patients with severe OSA had significantly higher serum LBP compared to patients with mild-moderate OSA $(p<0.05)$. After adjustments for age and BMI, serum LBP levels were significantly related to indices of central obesity (neck circumference and WHR), and to ODI (Table 3). ODI $(p=0.023)$ and WHR $(p=0.039)$ predicted serum LBP levels independently of age, smoking, hypertension, serum fasting glucose, triglycerides and HDL cholesterol levels in the multivariate regression analysis ( $p$ of the model=0.002, $\left.\quad r^{2}=0.154\right)$. We also analyzed an independent effect of an interaction term (WHR*ODI) on serum LBP levels, nevertheless, this interaction term did not reach statistical significance in the multivariate analysis. 
Table 1. Basic demographic characteristics and polysomnographic findings in subjects grouped by OSA severity.

\begin{tabular}{|c|c|c|c|c|c|}
\hline & $\begin{array}{l}\text { Entire cohort } \\
\qquad(n=117)\end{array}$ & $\begin{array}{c}\text { No OSA } \\
(n=10)\end{array}$ & $\begin{array}{l}\text { Mild - Moderate } \\
\text { OSA }(\mathbf{n}=\mathbf{5 0})\end{array}$ & $\begin{array}{l}\text { Severe OSA } \\
\quad(n=57)\end{array}$ & p (ANOVA) \\
\hline Age (years) & $46.5 \pm 9.50$ & $36.3 \pm 10.10$ & $45.3 \pm 9.20$ & $49.4 \pm 8.30 *$ & $<0.001$ \\
\hline$B M I\left(k g \cdot m^{-2}\right)$ & $30.3 \pm 4.20$ & $26.9 \pm 2.30$ & $29.4 \pm 3.60$ & $31.7 \pm 4.40^{* \dagger}$ & $<0.001$ \\
\hline Neck circumference (cm) & $43 \pm 3.00$ & $41 \pm 2.00$ & $42 \pm 3.00$ & $44 \pm 3.00 * \dagger$ & 0.006 \\
\hline Waist-to-hip ratio & $0.98 \pm 0.05$ & $0.95 \pm 0.07$ & $0.98 \pm 0.05$ & $1.00 \pm 0.05^{*}$ & 0.019 \\
\hline Current smoker, $n(\%)$ & 23 & $1(10.0)$ & $11(22.0)$ & $11(19.3)$ & 0.681 \\
\hline Arterial hypertension, $n(\%)$ & 41 & $1(10.0)$ & $18(36.0)$ & $22(38.6)$ & 0.213 \\
\hline BP systolic ( $\mathrm{mm} \mathrm{Hg})$ & $125.7 \pm 13.70$ & $110.5 \pm 8.00$ & $123.9 \pm 12.30$ & $130.0 \pm 13.70^{\dagger}$ & $<0.001$ \\
\hline BP diastolic ( $m m ~ H g)$ & $82.0 \pm 9.10$ & $76.0 \pm 9.40$ & $80.1 \pm 8.80$ & $84.7 \pm 8.40^{* \dagger}$ & 0.001 \\
\hline $\begin{array}{l}\text { Polysomnography NREM } \\
\text { (min) }\end{array}$ & $359 \pm 5$ & $349 \pm 59$ & $354 \pm 48$ & $367 \pm 38$ & 0.308 \\
\hline S1 NREM (min) & $55 \pm 34$ & $33 \pm 20.00$ & $49 \pm 28$ & $65 \pm 38^{* \dagger}$ & 0.002 \\
\hline$S 2 \operatorname{NREM}$ (min) & $242 \pm 55$ & $237 \pm 56.00$ & $236 \pm 52$ & $249 \pm 57$ & 0.410 \\
\hline$S W S(\min )$ & $65 \pm 37$ & $79 \pm 20.00$ & $71 \pm 39$ & $57 \pm 36$ & 0.063 \\
\hline$R E M(\min )$ & $69 \pm 29$ & $66 \pm 21.00$ & $74 \pm 30$ & $65 \pm 29$ & 0.233 \\
\hline AHI (events.hour ${ }^{-1}$ ) & $32.0 \pm 23.20$ & $2.8 \pm 1.10$ & $16.3 \pm 6.80^{*}$ & $50.1 \pm 18.90 * \dagger$ & $<0.001$ \\
\hline ODI (events.hour ${ }^{-1}$ ) & $27.2 \pm 24.40$ & $2.0 \pm 1.40$ & $11.6 \pm 8.40$ & $45.6 \pm 22.40 * \dagger$ & $<0.001$ \\
\hline Arousal index, (events. $\left.h^{-1}\right)$ & $38.3 \pm 22.00$ & $17.7 \pm 8.90$ & $25.3 \pm 11.70$ & $53.5 \pm 20.30 * \dagger$ & $<0.001$ \\
\hline $\mathrm{SpO}_{2}<90 \%$ (min) & $21.6 \pm 48.20$ & $0.0 \pm 0.10$ & $2.9 \pm 7.10$ & $46.0 \pm 64.80 *^{\dagger}$ & $<0.001$ \\
\hline Lowest $\mathrm{SpO}_{2}(\%)$ & $80.5 \pm 12.10$ & $92.2 \pm 1.90$ & $86.6 \pm 5.40 *$ & $73.0 \pm 12.80^{* \dagger}$ & $<0.001$ \\
\hline
\end{tabular}

Values are given as the mean $\pm \mathrm{SD}$, if not indicated otherwise. ${ }^{*} \mathrm{p}<0.05$ compared to no OSA. ${ }^{\dagger} \mathrm{p}<0.05$ compared to mild - moderate OSA. OSA, obstructive sleep apnea; BMI, body mass index; BP, blood pressure; NREM, non-rapid eye movement; S1, stage 1; S2, stage 2; SWS, slow wave sleep; REM, rapid eye movement; AHI, apnea/hypopnea index; ODI, oxygen desaturation index; $\mathrm{SpO}_{2}$, arterial oxygen saturation measured by pulse oximetry.

Table 2. Serum lipid and glucose metabolism markers in subjects grouped by OSA severity.

\begin{tabular}{|c|c|c|c|c|c|}
\hline & $\begin{array}{l}\text { Entire cohort } \\
\quad(n=117)\end{array}$ & $\begin{array}{c}\text { No OSA } \\
(n=10)\end{array}$ & $\begin{array}{c}\text { Mild - Moderate } \\
\text { OSA }(n=50)\end{array}$ & $\begin{array}{c}\text { Severe OSA } \\
\quad(n=57)\end{array}$ & p (ANOVA) \\
\hline Cholesterol $\left(\right.$ mmol. $\left.l^{-1}\right)$ & $5.30 \pm 1.01$ & $4.61 \pm 0.71$ & $5.30 \pm 0.96$ & $5.42 \pm 1.05$ & 0.060 \\
\hline Triglycerides $(\text { mmol.l })^{l}$ & $1.79 \pm 1.11$ & $1.31 \pm 0.50$ & $1.52 \pm 0.64$ & $2.12 \pm 1.39$ & 0.093 \\
\hline HDL cholesterol $\left(\right.$ mmol. $\left.l^{-1}\right)$ & $1.18 \pm 0.27$ & $1.14 \pm 0.20$ & $1.26 \pm 0.32$ & $1.11 \pm 0.22$ & 0.094 \\
\hline LDL cholesterol $\left(\right.$ mmol. $\left.l^{-1}\right)$ & $3.44 \pm 0.84$ & $3.00 \pm 0.78$ & $3.41 \pm 0.81$ & $3.54 \pm 0.87$ & 0.174 \\
\hline$L D L / H D L$ ratio & $3.02 \pm 0.79$ & $2.72 \pm 0.81$ & $2.83 \pm 0.82$ & $3.23 \pm 0.72^{\dagger}$ & 0.019 \\
\hline Atherogenic index ${ }^{\#}$ & $3.68 \pm 1.11$ & $3.15 \pm 0.81$ & $3.39 \pm 1.05$ & $4.01 \pm 1.11^{* \dagger}$ & 0.005 \\
\hline ApoA-1 $\left(g . l^{-1}\right)$ & $1.56 \pm 0.27$ & $1.48 \pm 0.22$ & $1.61 \pm 0.33$ & $1.54 \pm 0.23$ & 0.246 \\
\hline$A p o B\left(g \cdot l^{-1}\right)$ & $1.02 \pm 0.21$ & $0.89 \pm 0.19$ & $1.00 \pm 0.20$ & $1.07 \pm 0.21 *$ & 0.030 \\
\hline АроВ/АроA-1 & $0.67 \pm 0.16$ & $0.61 \pm 0.12$ & $0.64 \pm 0.16$ & $0.70 \pm 0.15$ & 0.046 \\
\hline $\operatorname{Lp}(a)\left(g . l^{-1}\right)$ & $21.09 \pm 28.70$ & $12.43 \pm 15.80$ & $23.88 \pm 33.59$ & $20.27 \pm 25.67$ & 0.503 \\
\hline Fasting glucose $\left(\right.$ mmol. $\left.l^{-1}\right)$ & $5.13 \pm 0.68$ & $4.77 \pm 0.57$ & $5.00 \pm 0.55$ & $5.31 \pm 0.76^{*}$ & 0.024 \\
\hline Fasting insulin $\left(\right.$ mmol. $\left.l^{-1}\right)$ & $12.18 \pm 8.50$ & $7.35 \pm 2.26$ & $11.37 \pm 6.72$ & $13.68 \pm 10.07 *$ & 0.026 \\
\hline$H O M A-I R$ & $2.85 \pm 2.31$ & $1.56 \pm 0.52$ & $2.56 \pm 1.58$ & $3.31 \pm 2.85^{*}$ & 0.008 \\
\hline
\end{tabular}

Values are given as the mean $\pm \mathrm{SD} .{ }^{*}$ Atherogenic index: (total cholesterol $-\mathrm{HDL}$ cholesterol).HDL cholesterol ${ }^{-1} .{ }^{*} \mathrm{p}<0.05$ compared to no OSA. ${ }^{+} \mathrm{p}<0.05$ compared to mild - moderate OSA. OSA, obstructive sleep apnea; HDL, high-density lipoprotein; LDL, low-density lipoprotein; Apo, apolipoprotein; Lp, lipoprotein; HOMA-IR, homeostasis model assessment. 


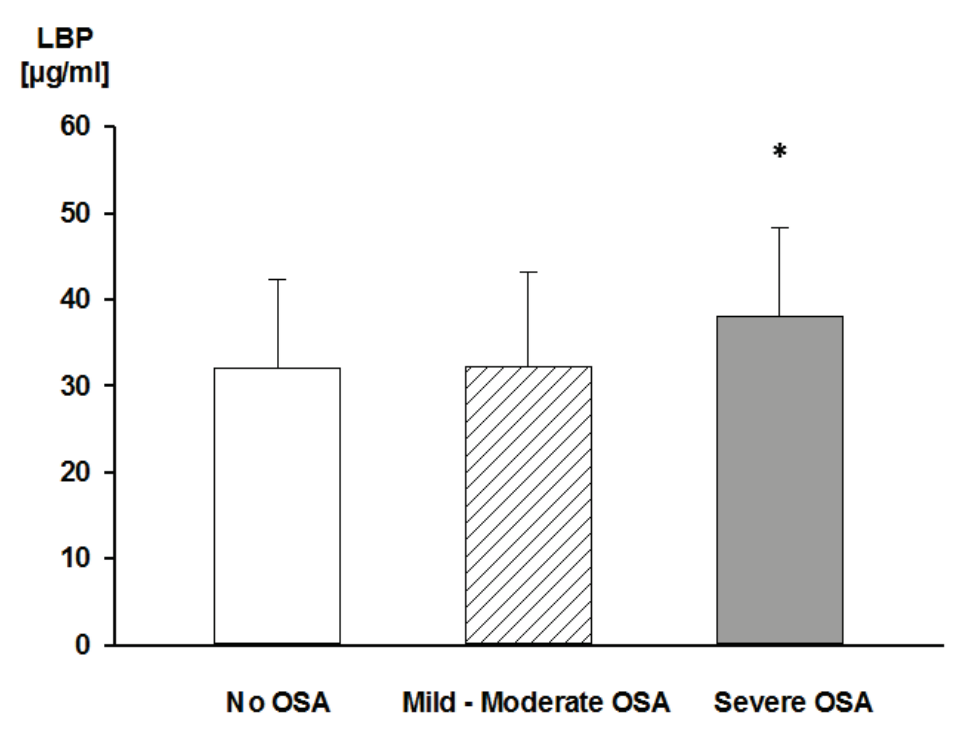

Fig. 1. Comparison of circulating lipopoly-saccharidebinding protein (LBP) levels in patients without obstructive sleep apnea (OSA), patients with mildmoderate OSA and patients with severe OSA (ANOVA, $p=0.015)$. $* p<0.05$ compared to mild - moderate OSA.

Table 3. Linear relationships between serum concentrations of LBP and atherosclerosis risk factors.

\begin{tabular}{|c|c|c|c|c|}
\hline Variable & $\begin{array}{c}\text { Pearson correlation } \\
\text { coefficient }^{*}\end{array}$ & p Value* & Beta coefficient $^{\dagger}$ & p Value ${ }^{\dagger}$ \\
\hline Age & 0.167 & 0.073 & - & - \\
\hline$B M I$ & 0.274 & 0.003 & - & - \\
\hline Neck circumference & 0.323 & $<0.001$ & 0.260 & 0.039 \\
\hline Waist-to-hip ratio & 0.343 & $<0.001$ & 0.250 & 0.028 \\
\hline Total Cholesterol & 0.086 & 0.362 & 0.053 & 0.570 \\
\hline HDL cholesterol & -0.127 & 0.190 & -0.044 & 0.653 \\
\hline Triglycerides & 0.122 & 0.203 & 0.076 & 0.416 \\
\hline LDL/HDL cholesterol & 0.194 & 0.043 & 0.095 & 0.339 \\
\hline Atherogenic index & 0.180 & 0.061 & 0.076 & 0.448 \\
\hline$A p o B$ & 0.118 & 0.223 & 0.074 & 0.438 \\
\hline ApoB/ApoA1 & 0.119 & 0.221 & 0.031 & 0.755 \\
\hline Fasting glucose & 0.171 & 0.068 & 0.046 & 0.647 \\
\hline$H O M A-I R$ & 0.252 & 0.009 & 0.169 & 0.082 \\
\hline Arterial hypertension & $0.280^{\#}$ & 0.002 & 0.195 & 0.055 \\
\hline$A H I$ & 0.302 & $<0.001$ & 0.184 & 0.101 \\
\hline$O D I$ & 0.333 & $<0.001$ & 0.232 & 0.045 \\
\hline Neutrophil count & 0.126 & 0.181 & 0.047 & 0.619 \\
\hline
\end{tabular}

* Unadjusted. ${ }^{\dagger}$ Adjusted for age and BMI. \# Spearman Rho correlation coefficient. LBP, lipopolysaccharide-binding protein; BMI, body mass index; LDL, low-density lipoprotein; HDL, high-density lipoprotein; Apo, apolipoprotein; HOMA-IR, homeostasis model assessment; $\mathrm{AHI}$, apnea/hypopnea index; ODI, oxygen desaturation index.

\section{Carotid intima-media thickness}

Both the right and left common CIMT increased from participants with no OSA to patients with mildmoderate and severe OSA $(\mathrm{p}=0.006 ; \mathrm{p}=0.002$, respectively) (Table 4). Figure 2 illustrates the average CIMT in subjects with no OSA, patients with mild-moderate and those with severe OSA
$(0.52 \pm 0.09 \mathrm{~mm}$ vs. $0.58 \pm 0.06 \mathrm{~mm}$ vs. $0.62 \pm 0.10 \mathrm{~mm}$, $\mathrm{p}=0.004)$. Patients with severe OSA had higher average CIMT compared to subjects with no OSA $(\mathrm{p}<0.05)$.

Figure 3 illustrates direct relationship between average CIMT and serum LBP levels ( $\mathrm{r}=0.287, \mathrm{p}=0.002)$. In multivariate analysis with average CIMT as the dependent variable and age, WHR, ODI, arterial 
hypertension, serum cholesterol, smoking and serum LBP levels as independent variables, the following variables independently predicted CIMT: age $(\mathrm{p}<0.001)$, cholesterol $(p=0.041)$, smoking $(p=0.039)$ and serum
LBP $(p=0.012)$ ( $p$ of the model $\left.<0.001, r^{2}=0.321\right)$. Thus serum LBP was retained in the model as a significant predictor of -CIMT independently of WHR.

Table 4. Carotid intima-media thickness in subjects grouped by OSA severity.

\begin{tabular}{lccccc}
\hline & $\begin{array}{c}\text { Entire cohort } \\
(\mathbf{n = 1 1 7})\end{array}$ & $\begin{array}{c}\text { No OSA } \\
\mathbf{( n = 1 0 )}\end{array}$ & $\begin{array}{c}\text { Mild - Moderate } \\
\text { OSA }(\mathbf{n = 5 0 )}\end{array}$ & $\begin{array}{c}\text { Severe OSA } \\
(\mathbf{n = 5 7 )}\end{array}$ & p (ANOVA) \\
\hline CIMT right $(\mathrm{mm})$ & $0.58 \pm 0.09$ & $0.53 \pm 0.09$ & $0.57 \pm 0.07$ & $0.61 \pm 0.10^{* \dagger}$ & 0.006 \\
CIMT left $(\mathrm{mm})$ & $0.61 \pm 0.11$ & $0.52 \pm 0.09$ & $0.60 \pm 0.08$ & $0.64 \pm 0.12^{* \dagger}$ & 0.002 \\
CIMT average $(\mathrm{mm})$ & $0.60 \pm 0.09$ & $0.52 \pm 0.09$ & $0.58 \pm 0.06$ & $0.62 \pm 0.10^{*}$ & 0.004 \\
\hline
\end{tabular}

Values are given as the mean $\pm \mathrm{SD} . * \mathrm{p}<0.05$ compared to no OSA. ${ }^{\dagger} \mathrm{p}<0.05$ compared to mild - moderate OSA. OSA, obstructive sleep apnea; CIMT, carotid intima-media thickness.
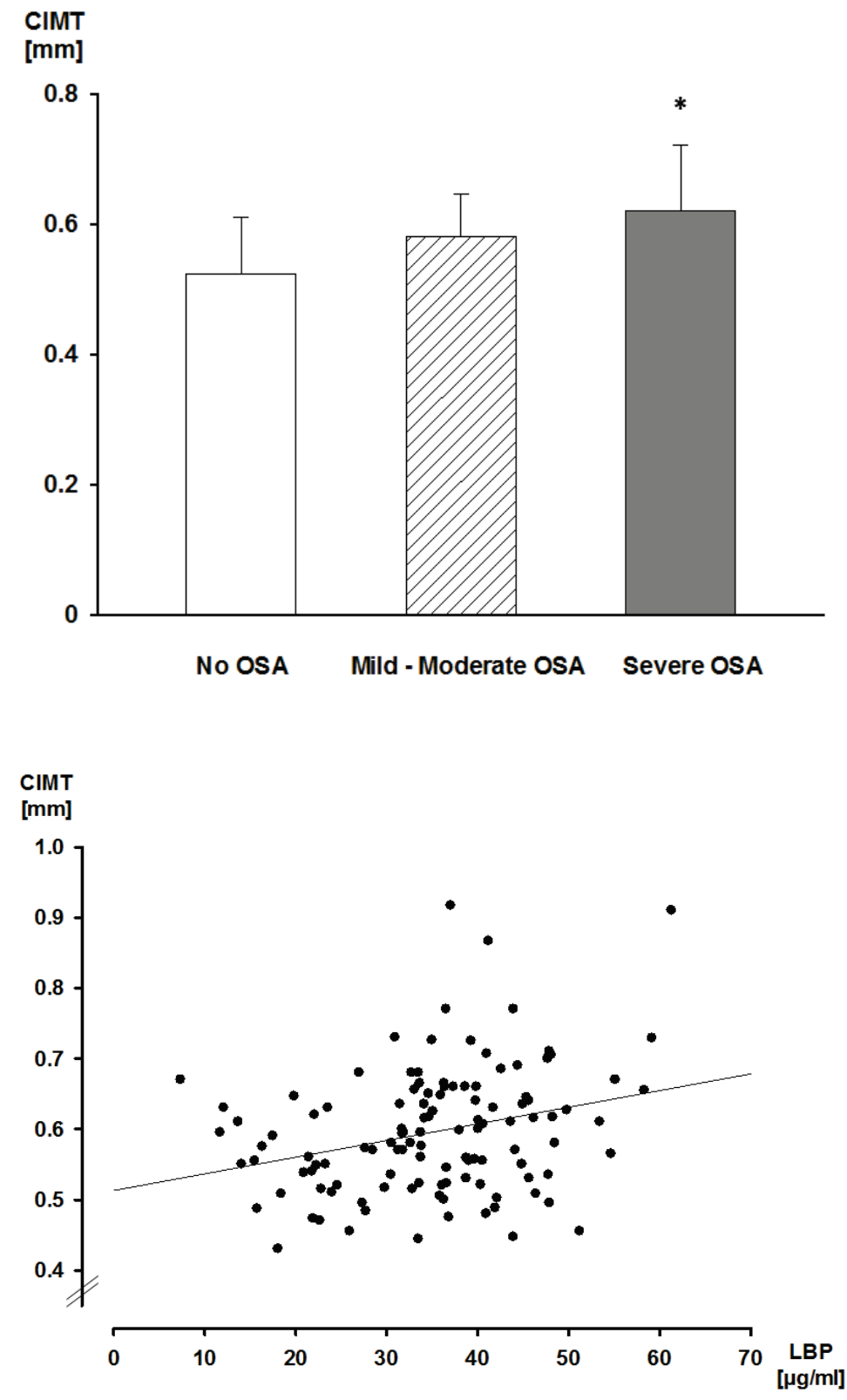

Fig. 2. Comparison of average carotid intima-media thickness (CIMT) in patients without obstructive sleep apnea (OSA), patients with mild-moderate OSA and patients with severe OSA (ANOVA, $p=0.004$ ). $* p<0.05$ compared to no OSA.

Fig. 3. Linear relationship between average carotid intima-media thickness (CIMT) and serum lipopolysaccharide-binding protein (LBP) levels ( $r=0.287$, $\mathrm{p}=0.002$ ). 


\section{Discussion}

The present study provides a novel observation on the relationship between OSA severity, endotoxemia and subclinical atherosclerosis in patients with OSA. Our data demonstrate increases in serum LBP concentrations in patients with severe OSA, in association with increases in CIMT. OSA severity as reflected by ODI was related to metabolic endotoxemia independently of obesity. Furthermore, serum LBP levels predicted CIMT independently of other known risk factors of atherosclerosis including obesity. Recently, low-grade endotoxemia was observed in children with OSA (Kheirandish-Gozal et al. 2014), and relationships between snoring (but no OSA) and higher LBP were demonstrated in adults (Sun et al. 2011). Nevertheless, these studies did not evaluate an independent effect of OSA on LBP levels, and in addition no direct assessment of clinical or subclinical atherosclerosis was performed. Therefore, by concomitant assessment of OSA severity, serum LBP levels and CIMT, our findings are the first to suggest that OSA severity as reflected by ODI relates to metabolic endotoxemia, and that endotoxemia is linked to increases in CIMT in adult patients with OSA. Importantly, the observed relationships were independent of the confounding effects of obesity.

LBP is an endogenously produced biomarker produced by hepatocytes, intestinal epithelial cells and adipocytes in response to intestinal microbial translocation, i.e. in response to the movement of gut microbial species or their products across intestinal mucosal barrier without overt bacteremia (Cani et al. 2008, Teixeira et al. 2012, Patel et al. 2015). LBP binds LPS in various pathologic states including obesity and insulin resistance, which are recognized as leading clinical conditions associated with endotoxemia (Kim et al. 2016, Boutagy et al. 2016). In agreement with previous reports our data demonstrate relationships between serum LBP and parameters of central obesity and insulin sensitivity (Gonzalez-Quintela et al. 2013, Kheirandish-Gozal et al. 2014, Sun et al. 2011, Zhu et al. 2016), and extend these findings further by suggesting an independent effect of OSA on serum LBP levels. The presence of intermittent episodes of hypoxia during sleep due to the repetitive apnea-hypopneas is a hallmark of OSA that links this disorder to its comorbidities (Dewan et al. 2015). Indeed, in our recent study we have documented that ODI provides a solid reflection of the degree of intermittent hypoxemia during sleep that predicts arterial hypertension in OSA patients (Tkacova et al. 2014). The role of hypoxia is further supported by the present results that suggest that ODI is related to serum LBP levels independently of the confounding effects of central obesity and other confounders. Which mechanisms might link chronic hypoxia to increases in endotoxemia markers? Several pathogenetic pathways are likely involved such as hypoxia-induced deterioration in the intestinal barrier function (Chun et al. 2016, Shah et al. 2016), and activation of different cellular adaptive mechanisms in hepatocytes (Liu et al. 2014, Savransky et al. 2007, Savransky et al. 2007). Hypoxia-inducible factor (HIF) transcription factors represent master regulators of the cellular responses to the hypoxia that might be key elements also in the control of immune cell metabolism and functionality (Palazon et al. 2014). Nevertheless, assessment of these mechanisms was beyond the scope of the present investigation, and thus further studies are needed to explore the pathogenetic links between hypoxia and metabolic endotoxemia.

Recent studies identified serum LBP as a significant and independent predictor of cardiovascular morbidity and mortality which significantly increased the research and clinical interests in assessing circulating LBP levels. Serrano et al. (2013) documented a consistent association between serum LBP and the CIMT within the FLORINASH project. Moreover, Lepper et al. (2007) observed significantly increased LBP in patients with angiographically documented coronary disease compared with angiographically negative patients, and in another study demonstrated that circulating LBP was a significant and independent predictor of total and cardiovascular mortality (Lepper et al. 2011). Moreover, consistent associations were observed between serum LBP and CIMT in other disorders such as patients in chronic peritoneal dialysis (Szeto et al. 2008). Our present report extends these previous observations by demonstrating increases in serum LBP in association with increased CIMT in patients with severe OSA, independently of other risk factors of atherosclerosis. To the best of our knowledge, this is the first study that reports a relationship between endotoxemia and subclinical atherosclerosis in patients with sleep disordered breathing, a condition associated with increased atherosclerotic morbidity and mortality (Marin et al. 2005, Ayas et al. 2016).

Multiple studies had linked OSA to the both traditional and novel risk factors of atherosclerosis such as arterial hypertension (Tkacova et al. 2014), the 
metabolic syndrome (Quian et al. 2016), systemic inflammation and oxidative stress (DeMartino et al. 2016). Our present findings coupled with reports of others (Lepper et al. 2011, Serrano et al. 2013) raise the possibility that LBP might, indeed, represent an additional risk factor of atherosclerosis. A question arises about the pathogenetic role of LBP in the development of the atherosclerotic plaque. LBP is the first protein to encounter LPS and to deliver it to its cellular targets, and thus it seems to be the first step in activating proinflammatory cascade of innate immune responses, which plays an important role in the pathophysiology of atherosclerosis (Ding et al. 2014, Schumann et al. 2011). Nevertheless, further studies are needed to thoroughly investigate the role of LBP as a cardiovascular risk factor.

Studying a well-defined cohort of adult men with OSA who all underwent full attended overnight polysomnography represents one of the main strengths of this study. Importantly, for the assessment of CIMT we have used an automatically based method that is both precise and highly reproducible (Bauer et al. 2012). There are several limitations to this study that need to be acknowledged. First, only a limited number of subjects were studied. However, compared to participants with no OSA, patients with severe OSA had mean CIMT values increased by $19 \%$, which was associated with increases in serum LBP by $12 \%$. Therefore, although our results are robust to gain some understanding on the role of LBP in OSA-related increases in CIMT, they should be considered preliminary and hypothesis generating. In addition, cross-sectional nature of the present study does not allow for the determination of time-course relationship between LBP and CIMT.

In conclusion, our study highlights associations between OSA severity, endotoxemia and CIMT in patients with OSA that are independent of other known risk factors of atherosclerosis including obesity. Further studies are needed to address the pathological mechanisms underlying the observed relationships in more details.

\section{Conflict of Interest}

There is no conflict of interest.

\section{Acknowledgements}

This work was supported by the Slovak Research and Development Agency of the Ministry of Education, Slovakia (APVV-0134-11), and grants VEGA 1/0863/15, VEGA $1 / 0208 / 16$. The authors wish to express their gratitude to Mrs. Anna Schejbalova and Mrs. Zuzana Lazarova, the technicians in the Sleep Laboratory, Department of Respiratory Medicine, Safarik University, Medical Faculty and L. Pasteur University Hospital, Kosice, Slovakia.

\section{References}

AYAS NT, TAYLOR CM, LAHER I: Cardiovascular consequences of obstructive sleep apnea. Curr Opin Cardiol 31: 599-605, 2016.

BAUER M, CAVIEZEL S, TEYNOR A, ERBEL R, MAHABADI AA, SCHMIDT-TRUCKSÄSS A: Carotid intima-media thickness as a biomarker of subclinical atherosclerosis. Swiss Med Wkly 142: w13705, 2012.

BERRY RB, BUDHIRAJA R, GOTTLIEB DJ, GOZAL D, IBER C, KAPUR VK, MARCUS CL, MEHRA R, PARTHASARATHY S, QUAN SF, ET AL.: Rules for scoring respiratory events in sleep: update of the 2007 AASM Manual for the Scoring of Sleep and Associated Events. Deliberations of the Sleep Apnea Definitions Task Force of the American Academy of Sleep Medicine. J Clin Sleep Med 8: 597-619, 2012.

BOUTAGY NE, MCMILLAN RP, FRISARD MI, HULVER MW: Metabolic endotoxemia with obesity: Is it real and is it relevant? Biochimie 124: 11-20, 2016.

CANI PD, BIBILONI R, KNAUF C, WAGET A, NEYRINCK AM, DELZENNE NM, BURCELIN R: Changes in gut microbiota control metabolic endotoxemia-induced inflammation in high-fat diet-induced obesity and diabetes in mice. Diabetes 57: 1470-1481, 2008.

CHUN C, ZHENG L, COLGAN SP: Tissue metabolism and host-microbial interactions in the intestinal mucosa. Free Radic Biol Med 105: 86-92, 2017.

DAMIANI MF, ZITO A, CARRATÙ P, FALCONE VA, BEGA E, SCICCHITANO P, CICCONE MM, RESTA O: Obstructive sleep apnea, hypertension, and their additive effects on atherosclerosis. Biochem Res Int 2015 : $84193,2015$. 
DEMARTINO T, GHOUL RE, WANG L, BENA J, HAZEN SL, TRACY R, PATEL SR, AUCKLEY D, MEHRA R: Oxidative stress and inflammation differentially elevated in objective versus habitual subjective reduced sleep duration in obstructive sleep apnea. Sleep 39: 1361-1369, 2016.

DEWAN NA, NIETO FJ, SOMERS VK: Intermittent hypoxemia and OSA: implications for comorbidities. Chest 147: 266-274, 2015.

DING PH, JIN LJ: The role of lipopolysaccharide-binding protein in innate immunity: a revisit and its relevance to oral/periodontal health. J Periodontal Res 49: 1-9, 2014.

DRAGER LF, BORTOLOTTO LA, LORENZI MC, FIGUEIREDO AC, KRIEGER EM, LORENZI-FILHO G: Early signs of atherosclerosis in obstructive sleep apnea. Am J Respir Crit Care Med 172: 613-618, 2005.

FOX N, AYAS N, PARK JE, FLEETHAM J, FRANK RYAN C, LEAR SA, MULGREW A, CHAN S, HILL J, JOHN MANCINI GB, WONG GC: Carotid intima media thickness in patients with obstructive sleep apnea: comparison with a community-based cohort. Lung 192: 297-303, 2014.

GAYOSO-DIZ P, OTERO-GONZÁLEZ A, RODRIGUEZ-ALVAREZ MX, GUDE F, GARCÍA F, DE FRANCISCO A, QUINTELA AG: Insulin resistance (HOMA-IR) cut-off values and the metabolic syndrome in a general adult population: effect of gender and age: EPIRCE cross-sectional study. BMC Endocr Disord 13: 47, 2013.

GONZALEZ-QUINTELA A, ALONSO M, CAMPOS J, VIZCAINO L, LOIDI L, GUDE F: Determinants of serum concentrations of lipopolysaccharide-binding protein (LBP) in the adult population: the role of obesity. PLoS One 8: e54600, 2013.

KHEIRANDISH-GOZAL L, PERIS E, WANG Y, TAMAE KAKAZU M, KHALYFA A, CARRERAS A, GOZAL D: Lipopolysaccharide-binding protein plasma levels in children: effects of obstructive sleep apnea and obesity. J Clin Endocrinol Metab 99: 656-663, 2014.

KIM KE, CHO YS, BAEK KS, LI L, BAEK KH, KIM JH, KIM HS, SHEEN YH: Lipopolysaccharide-binding protein plasma levels as a biomarker of obesity-related insulin resistance in adolescents. Korean J Pediatr 59: 231-238, 2016.

LEPPER PM, KLEBER ME, GRAMMER TB, HOFFMANN K, DIETZ S, WINKELMANN BR, BOEHM BO, MÄRZ W: Lipopolysaccharide-binding protein (LBP) is associated with total and cardiovascular mortality in individuals with or without stable coronary artery disease--results from the Ludwigshafen Risk and Cardiovascular Health Study (LURIC). Atherosclerosis 219: 291-297, 2011.

LEPPER PM, SCHUMANN C, TRIANTAFILOU K, RASCHE FM, SCHUSTER T, FRANK H, SCHNEIDER EM, TRIANTAFILOU M, VON EYNATTEN M: Association of lipopolysaccharide-binding protein and coronary artery disease in men. J Am Coll Cardiol 50: 25-31, 2007.

LIBBY P: Inflammation and atherosclerosis. Nature 420: 868-874, 2002.

LIU Y, MA Z, ZHAO C, WANG Y, WU G, XIAO J, MCCLAIN CJ, LI X, FENG W: HIF-1 $\alpha$ and HIF-2 $\alpha$ are critically involved in hypoxia-induced lipid accumulation in hepatocytes through reducing PGC-1 $\alpha$-mediated fatty acid $\beta$-oxidation. Toxicol Lett 226: 117-123, 2014.

MARIN JM, CARRIZO SJ, VICENTE E, AGUSTI AG: Long-term cardiovascular outcomes in men with obstructive sleep apnea-hypopnea with or without treatment with continuous positive airway pressure: an observational study. Lancet 365: 1046-1053, 2005.

MONNERET D, PEPIN JL, GODIN-RIBUOT D, DUCROS V, BAGUET JP, LEVY P, FAURE P: Association of urinary 15-F2t-isoprostane level with oxygen desaturation and carotid intima-media thickness in nonobese sleep apnea patients. Free Radic Biol Med 48: 619-625, 2010.

PALAZON A, GOLDRATH AW, NIZET V, JOHNSON RS: HIF transcription factors, inflammation, and immunity. Immunity 41: 518-528, 2014.

PATEL PN, SHAH RY, FERGUSON JF, REILLY MP: Human experimental endotoxemia in modeling the pathophysiology, genomics, and therapeutics of innate immunity in complex cardiometabolic diseases. Arterioscler Thromb Vasc Biol 35: 525-534, 2015.

PUNJABI NM, CAFFO BS, GOODWIN JL, GOTTLIEB DJ, NEWMAN AB, O'CONNOR GT, RAPOPORT DM, REDLINE S, RESNICK HE, ROBBINS JA, ET AL.: Sleep-disordered breathing and mortality: a prospective cohort study. PLoS Med 6: e1000132, 2009. 
QIAN Y, XU H, WANG Y, YI H, GUAN J, YIN S: Obstructive sleep apnea predicts risk of metabolic syndrome independently of obesity: a meta-analysis. Arch Med Sci 12: 1077-1087, 2016.

SAVRANSKY V, BEVANS S, NANAYAKKARA A, LI J, SMITH PL, TORBENSON MS, POLOTSKY VY: Chronic intermittent hypoxia causes hepatitis in a mouse model of diet-induced fatty liver. Am J Physiol Gastrointest Liver Physiol 293: G871-G877, 2007.

SAVRANSKY V, NANAYAKKARA A, VIVERO A, LI J, BEVANS S, SMITH PL, TORBENSON MS, POLOTSKY VY: Chronic intermittent hypoxia predisposes to liver injury. Hepatology 45: 1007-1013, 2007.

SCHUMANN RR: Old and new findings on lipopolysaccharide-binding protein: a soluble pattern-recognition molecule. Biochem Soc Trans 39: 989-993, 2011.

SERRANO M, MORENO-NAVARRETE JM, PUIG J, MORENO M, GUERRA E, ORTEGA F, XIFRA G, RICART W, FERNÁNDEZ-REAL JM: Serum lipopolysaccharide-binding protein as a marker of atherosclerosis. Atherosclerosis 230: 223-227, 2013.

SHAH NA, YAGGI HK, CONCATO J, MOHSENIN V: Obstructive sleep apnea as a risk factor for coronary events or cardiovascular death. Sleep Breath 14: 131-136, 2010.

SHAH YM: The role of hypoxia in intestinal inflammation. Mol Cell Pediatr 3: 1, 2016.

SUN L, PAN A, YU Z, LI H, SHI A, YU D, ZHANG G, ZONG G, LIU Y, LIN X: Snoring, inflammatory markers, adipokines and metabolic syndrome in apparently healthy Chinese. PLoS One 6: e27515, 2011.

SZETO CC, KWAN BC, CHOW KM, LAI KB, CHUNG KY, LEUNG CB, LI PK: Endotoxemia is related to systemic inflammation and atherosclerosis in peritoneal dialysis patients. Clin J Am Soc Nephrol 3: 431-436, 2008.

TEIXEIRA TF, COLLADO MC, FERREIRA CL, BRESSAN J, PELUZIO MDO C: Potential mechanisms for the emerging link between obesity and increased intestinal permeability. Nutr Res 32: 637-647, 2012.

TKACOVA R, MCNICHOLAS WT, JAVORSKY M, FIETZE I, SLIWINSKI P, PARATI G, GROTE L, HEDNER J, EUROPEAN SLEEP APNOEA DATABASE STUDY COLLABORATORS: Nocturnal intermittent hypoxia predicts prevalent hypertension in the European Sleep Apnoea Database cohort study. Eur Respir J 44: 931-941, 2014.

TOUBOUL PJ, HENNERICI MG, MEAIRS S, ADAMS H, AMARENCO P, BORNSTEIN N, CSIBA L, DESVARIEUX M, EBRAHIM S, HERNANDEZ HERNANDEZ R, ET AL.: Mannheim carotid intima-media thickness and plaque consensus (2004-2006-2011). An update on behalf of the advisory board of the 3rd, 4th and 5th watching the risk symposia, at the 13th, 15th and 20th European Stroke Conferences, Mannheim, Germany, 2004, Brussels, Belgium, 2006, and Hamburg, Germany, 2011. Cerebrovasc Dis 34: 290-296, 2012.

ZHU Q, ZHOU H, ZHANG A, GAO R, YANG S, ZHAO C, WANG Y, HU J, GOSWAMI R, GONG L, LI Q: Serum LBP is associated with insulin resistance in women with PCOS. PLoS One 11: e0145337, 2016. 